\title{
A infância em Piaget e o infantil em Freud: temporalidades e moralidades em questão
}

\author{
Maria Regina Maciel \\ Universidade do Estado do Rio de Janeiro - Rio de Janeiro - RJ - Brasil \\ Karla Patrícia Holanda Martins \\ Universidade Federal do Ceará- Fortaleza - CE - Brasil \\ Jesus Garcia Pascual \\ Professor da Universidade Federal do Ceará - CE - Brasil \\ Osterne Nonato Maia Filho \\ Universidade Estadual do Cearáe Universidade de Fortaleza- CE - Brasil
}

\section{Resumo}

O presente artigo propõe uma abordagem comparativa entre as noções de infância em Jean Piaget e de infantil em Sigmund Freud, tomando como conceitos básicos a noção de tempo e de moral em ambos os autores. Sustenta-se ser possível afirmar, a partir de uma leitura da epistemologia genética, que a infância vai-se transformando à medida que agimos e conhecemos de acordo com estruturas cognitivas operatórias. No entanto, segundo a psicanálise, é possível nos remeter ao infantil, presente também na vida adulta. O infantil escapa à racionalidade que subjaz àquela noção de estrutura piagetiana. A permanência do infantil é fonte das experiências criativas e da instauração de um movimento permanente de subjetivação.

Palavras-chave: Infantil; infância; tempo.

\section{Childhood in Piaget and infancy in Freud: temporality andmoralities}

\begin{abstract}
This article proposes a comparative approach between childhood notions of Jean Piaget and infancy in Sigmund Freud, it takes as basic concepts the notion of time and moral in both authors. It claims to be possible to state, from a reading of genetic epistemology, that childhood will be transformed as we act and we know according to operative cognitive structures. However, according to psychoanalysis, it is possible to refer to infancy, also present in adulthood. The infancy escapes the rationality that underlies to that notion of Piaget's structure. The permanence of the infancy is a source of creative experiences and the establishment of a permanent movement of subjectivity.
\end{abstract}

Keywords: Infancy; childhood; time.

\section{La infancia en Piaget y el infantil en Freud: Temporalidad y moralidades}

\section{Resumen}

El presente artículo propone un abordaje comparativo entre las nociones de infancia en Jean Piaget y de infantil en Sigmund Freud, tomando como conceptos básicos la noción de tiempo y de moral en ambos autores. Se sostiene ser posible afirmar, a partir de una lectura de la epistemología genética, que la infancia se va transformando a medida que actuamos y conocemos de acuerdo con estructuras cognitivas operatorias. Sin embargo, según el psicoanálisis, es posible remeternos al infantil, presente también en la vida adulta. El infantil escapa a la racionalidad que refuerza a aquella noción de estructura piagetiana. La permanencia del infantil es fuente de las experiencias creativas y de la instauración de un movimiento permanente de subjetivación.

Palabras clave: Infantil; infancia; tiempo. 


\section{Introdução}

A compreensão que se tem de infância e de infantil é marcada pela trama conceitual própria à teoria que a sustenta. O objetivo de nossa reflexão éfazer um recorte que nos permita comparar e distinguir a concepção de infância extraída do campo de uma psicologia do desenvolvimento, especificamente da teoria de Piaget, e a concepção do que chamamos de infantil no campo da psicanálise. Mais do que distingui-las pelos procedimentos investigativos, seja por observações empíricas, da psicologia com crianças ou a partir da escuta das representações inconscientes - no caso dapsicanálise, vamos diferenciá-los a partir de suas fundamentações teóricas e tramas conceituais.

Passando pelas ideias psicológicas que marcaram o Brasil nas últimas décadas acerca da infância, pensamos que a psicanálise não foi compreendida em sua radicalidade na perspectiva do lugar conferido ao infantil (Martins, Matos, \& Maciel, 2009; Maciel, 2011). Da mesma forma também julgamos que a obra de Jean Piaget (1896-1980) admitiu várias leituras de acordo com o interesse do pesquisador e a finalidade de sua investigação (Pascual \& Dias, 2004). Em outros termos, a preocupação epistemológica que percorreu os livros de Piaget, como por exemplo a forma como se passa de um conhecimento de menor consistência científica para outro de maior consistência, pode ser abordada de várias maneiras.

Adiantando o que teremos oportunidade de explorar no próximo subitem deste artigo, isso significa dizer que o objetivo de Piaget pode ser interpretado não como o de compreender a psicologia infantil, as crianças concretas indivíduos recortados pela cultura e pela sociedade -, mas o de compreender as características do "sujeito epistêmico", aquilo que é comum no desenvolvimento de todos os sujeitos, no que tange à inteligência, à afetividade, à socialização e à moralidade. $\mathrm{O}$ autor genebrino viu nas crianças concretas a possibilidade de defender o sujeito da Epistemologia Genética em contraponto as respostas à pergunta epistemológica dos paradigmas empiristas e aprioristas. Levando em conta seu viés epistemológico, cabe assinalar que o termo "criança" e o conceito que o engloba denota, na obra piagetiana, o período do nascimento até a puberdade. Este conceito foi estudado sob a perspectiva das estruturas sensório-motora (estágio sensório-motor), representativa (estágio pré-operatório) e operatórias (estágios operatórios concreto e abstrato).

A discussão acurada desse tema será feita no corpus deste artigo. Assim, procuramos cotejar as compreensões de Piaget e de Freud referentes ao papel relativo à temporalidade e à moralidade nos processos de constituição subjetiva. Tal questão é relevante, justamente por não serusualmente abordada quando sepretende entrelaçar esses dois pensadores. Abre-se, assim, uma nova perspectiva de análise qualitativa, teórica e explanatória que visa se debruçar sobre convergências e divergências entre as teorias de Piaget e de Freudanalisadaspor estudiosos da área.
O debate Piaget e Freud: por uma antropologia do desenvolvimento?

O debate entre os pensamentos de Piaget e de Freud no Brasil se tornou particularmente intenso nos anos $90 \mathrm{com}$ a obra de Lajonquière (1992), cuja tese se contrapunha àquela defendida por Dolle (1979). O argumento do último era de que a epistemologia psicanalítica havia centrado toda a sua tese no desenvolvimento afetivo do sujeito e dado pouca atenção à cognição e sua base egóica, enquanto a epistemologia genética de Piaget demonstraria que o desenvolvimento cognitivo leva ao domínio dos processos afetivos, expressivos e dos automatismos inconscientes. Nesse sentido, o percurso adequado para a psicologia do desenvolvimento deveria ser de Freud a Piaget.

Lajonquière (1992), por sua vez, defende uma argumentação contrária: deveríamos falar em um desenvolvimento infantil que levasse em conta a dimensão do inconsciente e suas características, aspecto pouco realçado por diversas leituras de Piaget no Brasil. Nesses termos poderíamos falar de uma tese inversa: de Piaget a Freud. No entanto, o objetivo deste ensaio não é defender quaisquer das duas teses, masdiscutir as aproximações e divergências entre eles, por meio do estudo dos termos infância no primeiro e infantil no segundo autor, estabelecendo-se como eixos norteadores os temas da temporalidade e da moralidade.

Em um texto clássico, Consciência social e sua história, Moscovici (2003) faz um resgate do conceito de representação social ao longo da história e resgata a influência da antropologia de Lévy-Bruhl no pensamento de Piaget. Argumenta Moscovici (2003): diferentemente da corrente behaviorista, claramente evolucionária, Piaget sob a influência de Lévy-Bruhl, em sua teoria de desenvolvimento infantil parte da formação cultural do homem; do homem como determinado e determinador da cultura e não da continuidade mundo animal e mundo humano.

Podemos claramente estender essa tese a Freud, não pelo fato de Lévy-Bruhl ter influenciado, igualmente, Freud, pois parece ter sido o contrário (Tambiah, 2013), mas porque também o que está em jogo para Freud, ao menos em sua primeira tópica do aparelho psíquico e em sua primeira teoria pulsional, é o inconsciente enquanto recalcado e não um inconsciente filogenético (Freud, 1921/1994f) ou o automatismo e a aprendizagem elementar do animal.

É fato que a tese central de Lévy-Bruhl é interpretada de forma muito diversa por esses estudiosos. Levy-Bruhl defende que a "mentalidade primitiva" não é inferior a mentalidade dita civilizada e lógico-racional, típica da cultura ocidental, mas segue uma lógica própria baseada na participação, na identificação afetiva e na linguagem analógica. Enquanto Freud vai visualizar na mente primitiva a onipotência narcísica da criança; Piaget visualiza na criança e no seu desenvolvimento a estrutura sobre a qual se erguerá o desenvolvimento adulto.

No entanto se é bastante razoável relacionar o funcionamento de processo primário de Freud, condensações e deslocamentos, à lei da relação e da participação em Lévy- 
-Bruhl e sua tese acerca das ditas "mentalidades primitivas", tal perspectiva parece se confrontar com o desenvolvimento do pensamento lógico-racional de Piaget como uma transformação daquelas. De fato, a leitura de Freud parece apontar para o erro piagetiano de se considerar o funcionamento da consciência lógico, racional, digital, típica da cultura ocidental moderna, como uma tendência universal (Tambiah, 2013).

A questão de fundo parece ser outra com relação ao desenvolvimento da infância em Piaget e do infantil em Freud: faz sentido separar o desenvolvimento afetivo e o cognitivo ou subsumir um ao outro, de Freud a Piaget ou de Piaget a Freud como queriam Dolle e Lajoquière?

Cabe aqui nos perguntar: onde Freud vê um registro psíquico, Piaget concebe uma etapa a ser ultrapassada? Afinal, se em Freud o narcisismo é constitutivo; em Piaget, a despeito de toda sua contribuição à compreensão do desenvolvimento da criança, o "primitivo" parece referir-se a esquemas mentais (sensorial-motor e pré-operatório) a serem ultrapassados, em nome de uma racionalidade adulta.

Freud, a despeito da onipotência narcísica e inconsciente da criança que precisa ser barrada pelo adulto, nos conduz a pensar em processos primários permanentes e criadores. Além disto, estes processos "primitivos" escapam ao domínio das estruturas simbólicas.

\section{A criança na perspectiva de Piaget: tempo e moral}

Como campo de nossa investigação a respeito da noção de "criança" em Piaget, escolhemos o primeiro [1920-1930] e o segundo [1930-1945] períodos da obra psicológica piagetiana, denominados de fase "chez l'enfant", acrescidos de dois livros e de um artigo, posteriores (1955, 1966 e 1954/2001), respectivamente. A “criança” aparece como campo privilegiado de estudos psicológicos; constata-se, contudo, que sua preocupação era conhecer a gênese de certos processos psicológicos sem se preocupar com definição do termo. Piaget publicou nesse período vários livros cujos títulos levam a pensar a palavra criança ("chez l'enfant"). Contudo, o autor estava mais preocupado em estudar os processos interativos da linguagem e do pensamento (1923); a representação infantil do mundo (1926/2005); o desenvolvimento do juízo moral (1932/1984); os primórdios da inteligência prática (1936/1966); a construção da realidade objetiva (1937) e, finalmente, a passagem da ação motora para a ação representada - formação do símbolo (1945a/1990).

A noção de criança, vista na perspectiva da temporalidade, aparece como a etapa primeira do desenvolvimento psicológico que é superada em fases posteriores: "O desenvolvimento mental da criança surge, em síntese, como sucessão de três grandes construções, cada uma das quais prolonga a anterior" (Piaget \& Inhelder, 1966/1994, p. 129). Perguntar-se pelo conceito de criança em Piaget implica inseri-lo na trama epistemológica de sua obra, isto é, afirmar que as estruturas cognitivas e afetivas da criança e as estruturas cognitivas e afetivas do adulto são qualitativamente diferentes, porque a etapa anterior é reconstruída primeiramente num plano novo e ultrapassada cada vez mais amplamente.

O termo "criança" abarca, também, a puberdade como segunda infância, conforme pode ser rastreado em seus escritos: “... o papel da autonomia concreta adquirida durante a segunda infância... sendo a adolescência (15-18 anos) a idade da inserção do indivíduo na sociedade adulta..." (Piaget \& Inhelder, 1966/1994, p. 127). Cabe observar, todavia, que o uso da palavra "criança" engloba simplesmente o período da infância até a adolescência: "A psicologia da criança estuda o crescimento mental... até a fase de transição constituída pela adolescência..." (p. 7). Há, pois, um corte nítido no uso do termo "criança" para se referir aos sujeitos quando eles atingem as operações proposicionais, que marcam a decalagem vertical no desenvolvimento cognitivo, afetivo e social: "A última descentração fundamental, que se realiza no termo da infância, prepara a liberação do concreto em proveito de interesses orientados para o inatual e o futuro" (Piaget \& Inhelder, 1966/1994, p. 111). O dilema aqui diz respeito a essa segunda infância, visto que coincide com o período em que essa passagem já ocorreu, por volta dos 11 anos de idade. Trata-se de um pensamento pré-adolescente e de transição?

Conhecer a noção de criança na obra piagetiana significa estudar as características dos estágios no que tange à cognição, à moralidade e à afetividade, já que formam uma unidade inextricável: “... algumas pessoas afirmam que o estudo do desenvolvimento intelectual cai no intelectualismo, isolando arbitrariamente a inteligência e desconhecendo as relações entre a vida intelectual e a afetividade" (Piaget, 1954/2001, p. 17).

Com relação à cognição, Piaget mostra que há diferença qualitativa entre a inteligência da criança e a do adolescente, o que significa que o pensamento infantil reveste-se maciçamente do egocentrismo, em contraposição à descentração típica da adolescência, isto é, a forma do pensamento da primeira gira em torno do seu próprio ponto de vista: "O egocentrismo infantil é essencialmente um fenômeno de indiferenciação: confusão do ponto de vista próprio com o de outrem, ou da ação das coisas e das pessoas com a própria atividade" (Piaget, 1946/1990b, p. 75). O pensamento infantil egocêntrico compõe-se de atributos como o realismo, o animismo e o artificialismo, formas sob as quais as crianças representam o mundo.

Nessa direção, a pergunta axial sobre o realismo infantil é: “... a criança é capaz de diferenciar o mundo exterior e seu mundo interior?" (Piaget, 1926/2005, p. 3). Piaget estuda o realismo do pensamento infantil primeiramente na identificação das palavras com os pensamentos e, nesse sentido, as crianças, até perto dos 11 anos, acham que pensar é falar, ou seja, pensa-se com a boca, as palavras são vozes que estão dentro da cabeça etc. O egocentrismo manifesta-se também sob a forma de realismo nominal no sentido de que os nomes fazem parte da essência das coisas, é uma qualidade inerente à coisa. Tal característica 
do realismo aparece estampada nos sonhos infantis, cujos conteúdos oníricos vêm de fora do sujeito e permanecem fora quando está sonhando.

O egocentrismo contém uma segunda característica denominada animismo, isto é, as crianças consideram também corpos vivos aqueles que os adultos consideram inertes (lua, sol, árvore etc.). Ao realismo e animismo Piaget acrescenta outra característica do pensamento infantil, o artificialismo, isto é, as crianças consideram as coisas (rios, astros, lagos etc.) como produtos fabricados pelas pessoas (Piaget, 1926/2005).Para Freud, por sua vez, tais processos diriam mais de uma etapa da adaptação do inconsciente à realidade na forma de desenvolvimento de um ego.

Segundo Piaget, o conceito "criança" designa, pois, pessoas cuja inteligência apresenta características de egocentrismo intenso que se resume na confusão entre significante e significado, entre interno e externo, entre pensamento e matéria. Segundo o autor, o realismo infantil acontece porque a criança não consegue perceber a existência da subjetividade em sua plenitude simbólica, fonte do pensamento; a rigor, para as crianças há uma única realidade, a exterior.

O intuito de Piaget não era avaliar os comportamentos das crianças entrevistadas; como elas agem, por exemplo, diante de dilemas morais, mas o julgamento que emitem diante de certas situações fictícias: "Propusemo-nos a estudar o juízo moral, e não os comportamentos ou sentimentos morais" (Piaget, 1932/1984, p. 21). Trata-se, portanto, da dimensão racional que norteia o julgamento de valores. E, ao pesquisar a dimensão cognitiva da moralidade, o autor genebrino descobre que ela é construída pelos sujeitos ao longo de seu desenvolvimento psicológico, opondo-se às teses filosóficas da moralidade inata. Se a construção de valores é um processo psicogenético, encontrar-se-ão características diferentes no julgamento das crianças e dos adultos.

É próprio da primeira infância (0-4 anos) não reconhecer a questão moral (como devo agir), isto é, onde radica a obrigatoriedade para realizar ou evitar determinados comportamentos. As crianças pequenas não reconhecem as normas no sentido de que algo deve ser evitado ou realizado segundo os preceitos de lei. E sendo assim, essa fase é denominada por Piaget de "anomia", ausência da concepção da existência de leis, de normas ou de regras que coordenem o convívio social e a preservação dos direitos do outro. As crianças respeitam as ordens pelo temor ao castigo e não porque compreendem a natureza da lei.

Na segunda infância, na fase de heteronomia moral (5-11 anos), as crianças reconhecem a lei como fonte ordenadora dos comportamentos, mas as leis são elaboradas por alguém muito importante e soberano; a lei é uma externalidade, vem do outro. Daí que proceder moralmente com correção significa obedecer a esse outrem superior: "A lei é inquestionável; perante ela só cabe uma atitude moralmente correta: a obediência" (Pascual, 1999, p. 5). É próprio das crianças agirem dessas duas fases, anomia e heteronomia, ou mesmo relacionarem-se com adultos mediante interações de coação, porque elas os vêm como superiores. As relações são verticais; daí o medo e a obediência! Trata-se também de uma lei retributiva: a sanção deve ser equivalente à falha cometida, como a lei do Talião: "olho por olho, dente por dente". Não há atenuantes, é uma lei tudo ou nada.

Nesse sentido é no momento em que os sujeitos não veem a lei mais como algo sagrado ou externo ao grupo que eles deixam de ser crianças, tornando-se adolescentes/ adultos, isto é, conseguem a autonomia moral: "A regra do jogo se apresenta à criança não mais como uma lei exterior, sagrada, enquanto imposta pelos adultos, mas como resultado de uma livre decisão, e como digna de respeito na medida em que é mutuamente consentida (Piaget, 1932/1984, p. 60)."

No que diz respeito à afetividade, Piaget vê seu desenvolvimento relacionado diretamente com a inteligência e essa relação é de tal ordem que ninguém nega sua constante interação (Piaget, 1954/2001, p. 17). Observa, contudo, que essa interação pode ser entendida sob dois aspectos: a) a afetividade estimula, acelera ou perturba as operações da inteligência; b) a afetividade ajuda na construção das estruturas cognitivas. Piaget conclui que a afetividade pode sim provocar acelerações ou retrocessos no desenvolvimento das estruturas da inteligência, mas “... não pode nem produzir nem modificar as estruturas” (Piaget, 1954/2001, p. 103). Trata-se, na verdade, de duas dimensões, uma estrutural, potencializada pela inteligência, e outra energética, potencializada pela afetividade. Ambas são isomorfas em todos os comportamentos. Nos comportamentos orientados para os objetos, o elemento estrutural (inteligência) é constituído pelas "diversas estruturas lógico-matemáticas", enquanto o elemento energético (afetividade) é constituído pelo interesse, pelos valores, pela interatividade e suas regulações (Piaget, 1954/2001, p. 104).

Mas como se manifesta a afetividade na infância? Nosso autor divide o seu desenvolvimento em cinco estágios: $1^{\circ}$ ) dispositivos hereditários - tendências instintivas de posição corporal, medos de escuro, de ruídos etc.; $2^{\circ}$ ) afetos perceptivos - prazer ligado à percepção de quente, frio, rosto de pessoas, etc.; $3^{\circ}$ ) afetos intencionais - sentimento de felicidade, de fadiga ao terminar uma tarefa etc.; $4^{\circ}$ ) afetos intuitivos e interindividuais - simpatia, obediência etc.; $5^{\circ}$ ) afetos normativos - justo, injusto etc.. Cabe sinalizar que ele ainda acrescenta o sexto, os sentimentos idealizados e formação da personalidade - papel na coletividade, idealismo etc., que aparecem nos alvores da adolescência, o que foge ao escopo deste trabalho.

Resumindo, fica claro ao longo da obra piagetiana que a criança não pode ser considerada como um pequeno adulto. Ser criança em relação ao adulto não se assemelha à maquete em relação ao prédio que ela representa. Significa possuir um arcabouço cognitivo, afetivo e moral específico, tecido na confusão entre a subjetividade e a objetividade inicial. Mas, a partir de quatro fatores, maturação, experiência física com os objetos, relacionamento social e autorregulação ou equilibração, a criança chega à vida adulta com o pleno desenvolvimento dessas três dimensões anteriormente citadas, a cognitiva, a afetiva e a moral. 
Como dito anteriormente, a característica egocêntrica da criança torna seu pensamento animista, artificialista e realista, o que, se por um lado dificulta a relação com a objetividade da realidade, por outro potencializa a fantasia, a imaginação, o sonho, o pensamento criativo. A criança que se aninha dentro do adulto permite que este sonhe $\mathrm{e}$ que faça poesia, que experimente novas percepções etc. Em contrapartida, o pensamento adulto caracteriza-se pela descentração, pela análise, pelas coordenações lógicas das ações, pela reversibilidade e transitividade das ações, pela conservação da quantidade e pelos aspectos operatórios do pensamento, que culmina com a predominância das transformações sobre as percepções. Nesse sentido, a criança, cuja assimilação é mais generalizadora e não respeita as peculiaridades das coisas, é obrigada a incorporar a acomodação na busca de equilibração mais consistente. De fato, é a acomodação que produz o novo, equilibração majorante, a despeito de toda "resistência" da criança.

Piaget defende energicamente que a diferença entre a inteligência da criança e a do adulto não é quantitativa, mas qualitativa. $\mathrm{O}$ adulto não pensa mais do que a criança, mas diferente. Portanto, o desenvolvimento do pensamento corre por trilhos diferentes da mera acumulação, porque evoluir é adquirir estruturas de conhecimento e afetivas mais complexas, por equilibrações majorantes, implicando em maior descentração e transitividade do sujeito.

\section{O infantil na perspectiva de Freud: o tempo do infantil}

Pode-se afirmar existir uma teoria sobre o desenvolvimento da infância orientada por pressupostos psicanalíticos? Em caso afirmativo, o que supomos como contribuições freudianas? No ensino das disciplinas de desenvolvimento, aplicadas, por exemplo, aos cursos de Psicologia (Martins \& cols., 2009), é comum privilegiar-se as ideias de Freud (1905/1994c) contidas nos seus ensaios sobre a sexualidade humana e suas indicações sobre os modos de fixação da libido. Em geral, as indicações freudianas são compreendidas numa referência ao tempo cronológico do desenvolvimento, fazendo coincidir sua compreensão à ideia de fases a serem superadas (as fases da libido - oral, anal, fálica, latência e genital), em direção a uma suposta normalidade do sexual.

Todavia, contrariamente a essa posição, ao se colocar no centro desta compreensão a ideia de uma temporalidade inconsciente, subverte-se o lugar conferido ao infantil que agora passa de uma condição a ser superada a um tempo de fundação, uma espécie de matriz que estrutura no a posteriori a vida psíquica, semelhante ao só depois que se observa após uma intervenção analítica. Aqui o infantil é definido como o entrelaçamento dos tempos, onde passado, presente e futuro, por não produzirem sínteses, convocam o psíquico a uma tentativa, permanente, de criar (Maciel, 2011). Não se espera aqui um progresso que vai do simples ao complexo, do desconhecimento ao conhecimento, tam- pouco da dependência à independência como em Piaget. Desse modo, o que constitui a matriz fundante do psiquismo em Freud?

Em sua metáfora do 'Bloco mágico', Freud (1924$1925 / 1994$ h) retoma a sua compreensão sobre o modo de funcionamento da memória e seu papel na constituição do sujeito psíquico, já anunciada em pelo menos dois momentos da sua correspondência com W. Fliess, hoje conhecidos como Carta 52(1892-1899/1994b) e Projeto para uma psicologia científica (1895/1994a). Freud retoma, nesse momento, a sua teoria sobre os modos de inscrição da experiência, onde não haveria sujeito sem um outro que participe ativamente do seu modo de estruturação. Desde sempre, nessa perspectiva, o orgânico e o psíquico fundam um corpo, numa referência à capacidade simbólica, através da mediação e presença deste outro primordial.

Assim, a memória é um registro de articulação entre o campo da pulsão e da linguagem, onde o que se inscreve como marca psíquica não é produto de uma síntese dialética de opostos, mas da afirmação da diferença no permanente contato com a experiência, pois o corpo pulsional já não é mais o corpo biológico, movido somente por um sistema de necessidades. Em se tratando de constituição psíquica, portanto, diluem-se os binarismos em nome das disseminações de termos complementares. Mais especificamente, termos como "força" corporal e "sentido" psíquico passam a serem vistas como complementares e não como opostos.

Nessa direção, Derrida (2011), no seu clássico estudo sobre o Bloco mágico de Freud, propõe pensar a escritura em termos de traços diferenciais, construídos numa rede de relações sempre aberta. Birman (2007) sugere que, com Freud e Derrida, podemos passar do âmbito da polissemia, no que ela deve à contradição dialética dos opostos, para o da disseminação, que nos remete a algo no qual os termos são complementares, o que é diverso da lógica binária); ou seja, das estruturas duais, tais como significante/significado, homem/mulher, corpo/linguagem, para a trama diferencial. Afinal, os binarismos precisam ser superados se quisermos comportar a lógica ambivalente e dialética de Freud.

Assim, ao pensarmos nas marcas inconscientes deixadas pelo outro em nós, o que pode ser traduzido nos traços de memória que vão constituindo nosso psiquismo, temos de pensar nas excitações que se disseminam e nas resistências que encontram para a descarga. $\mathrm{Na}$ inscrição dos traços no psiquismo, os registros da força e do sentido não estariam em oposição. Ao contrário, é no jogo das forças disseminadas e das resistências produzidas que os traços se inscrevem no psiquismo, podendo produzir sentidos.

No texto Projeto para uma psicologia científica, Freud (1895/1994a) propõe que diante de sua condição de desamparo fundamental, cada bebê humano precisa construir seu caminho rumo à constituição de um sujeito psíquico a partir de seu encontro com o semelhante. Posteriormente, Freud (1914/1994f) afirmará que o que ali se funda é efeito do narcisismo dos pais. Isso significa dizer que o que lhe antecede simbolicamente também cria condições de sua estruturação, num a posteriori. Desse modo, "não se trata, pois, do tempo 
cronológico, mas do tempo poético em que a simbólica revela assim sua ascendência" (Kaufmann, 1996, p. 173). É por isso que o egocentrismo infantil e sua onipotência narcísica não são meras dificuldades cognitivas a serem superadas como em Piaget, mas desejo, afeto, que produzem realidades: é preciso que essa condição se confirme para que adentremos nesse mundo simbólico, analógico, do futuro, em que a realidade, inclusive do tempo, não é um dado, mas uma relação. Trata-se do que Lévy-Bruhl chamou de mundo da participação em contraponto ao mundo lógico-formal (Tambiah, 2013).

Nessa perspectiva, a questão do infantil na psicanálise diz respeito ao tempo psíquico que não é somente o cronológico. Indicações de outros tempos podem ser encontradas em textos freudianos, como, por exemplo, O mal-estar na civilização (Freud, 1929-1930/1994j, p. 70). Neste, Freud sugere uma curiosa analogia do psiquismo com a "cidade eterna" de Roma, no sentido de ambos preservarem lado a lado diferentes etapas do seu desenvolvimento. Outra sugestão de temporalidade própria à psicanálise diz respeito ao tempo que não passa - quando Freud refere-se, por exemplo, a impulsos do Inconsciente que são "virtualmente imortais" (Freud, 1932-1933/1994k, p. 69).

Esses tempos de Freud nos permitem afirmar a permanência do infantil no adulto, infantil que nos remete ao potencial criativo e ao que não se resume a uma lógica binária. Ou ainda, como apontado anteriormente, o infantil seria origem e condição de possibilidade de uma história, posto que nele o outro, como alteridade radical, ainda não se inscreveu; em outras palavras, a história é o testemunho dessa inscrição. Como nos lembra Flusser (2010), é a escrita (inscrição) que produz a história e não o mundo binário das imagens.

Isso significa dizer que, em uma teoria do desenvolvimento, deve-se pensar nos tempos de constituição do sujeito psíquico, além, é claro, de se pensar nos processos de maturação orgânica. Todavia, aqui, esses termos são solidários, ou seja, a integridade neurofisiológica de um bebê não lhe garante suas condições de sobrevivência, o que para a psicanálise representará sempre a condição de estruturação de um sujeito psíquico colocada em referência aos campos pulsionais e simbólicos, respectivamente força e palavra. Desse modo, a escritura, no dizer de Coriat (1997), é produto da força (o material que escreve) e do papel (o material onde se inscreve).

\section{O infantil e a moral}

Na perspectiva freudiana, a moralidade relaciona-se à consciência do desamparo humano, ou seja, é associada à precoce percepção do bebê da sua dependência dos cuidados do ambiente. A criança adentra no universo moral ainda muito cedo à medida que percebe falhas decorrentes de suas necessidades, falhas necessárias e estruturantes. Todavia, o estabelecimento de uma instância responsável pela consciência moral é expressão de um deslocamento do bebê, no campo dos sentidos, de um medo de perder a vida para o medo de perder o amor do semelhante (Costa, 2010).

Fundamentado na hipótese do desamparo, Freud (1925/1994i) propôs ainda que a consciência moral estaria diretamente relacionada à capacidade de julgar, definida como uma espécie de ação intelectual que expressa uma escolha na forma como devo agir. A singularidade do pensamento freudiano reside no modo como engaja a dimensão sensória e perceptiva na escolha da ação ajuizada: o corpo pensa e escolhe. Freud (1925/1994i), indagando-se onde e quando o Eu teria aprendido essa técnica que agora ele aplica aos processos de pensamento, responde que a experiência de pensamento "ocorreu na extremidade sensorial do aparelho mental, junto às percepções sensoriais, pois de acordo com a nossa suposição, a percepção não é um processo passivo" (1925/1994i, p. 256).

Os processos de julgamento e, respectivamente, a manutenção ou não do investimento, correspondem, em outras palavras, à descontinuidade do funcionamento do sistema Pcpt.-Cs. (perceptivo-consciente) e estão, também, na origem do conceito de tempo. Nesse sentido, a possibilidade de a criança submeter seus processos de pensamento ao teste de realidade coincide com a sua capacidade de submetê-los a uma ordem temporal. Em outras palavras, a consciência moral corresponde ao reconhecimento da alteridade (que está sempre presente na constituição do psiquismo e não quer dizer, necessariamente, autoridade), a partir da tensão produzida na articulação das forças pulsionais com os registros da imaginação e do simbolismo.

Numa determinada perspectiva é possível afirmar que na base da moralidade humana, para a psicanálise freudiana, estão a formação de ideais e as identificações, inicialmente imaginárias (eu-ideal) e posteriormente simbólicas (ideal-do-eu ou supereu). Esta referência, contudo, a uma ordenação temporal na formação dos ideais, esquece, por outro lado, que em nossa subjetividade esses dois registros circulam cotidianamente.

A psicanálise, ao enlaçar linguagem e corpo, refere-se a um sujeito marcado pela contingência e pela história, produzindo-se no campo do discurso e no campo da pulsão. O que quer dizer isso? Quer dizer que nos produzimos na tensão entre o registro simbólico e o registro da força. Ao nos referirmos ao registro da força, um novo campo se abre. É a partir dele que queremos afirmar que o "infantil" diz respeito àquilo que de certa forma sempre escapa às tentativas de dominação por parte da sociedade, da racionalidade, do outro, etc. $\mathrm{O}$ que denominamos de infantil nos remete à moralidade que pode partir da consciência do desamparo, na qual nos submetemos à ordem temporal e reconhecemos a alteridade, conforme afirmamos no início deste subitem.

O infantil que subverte, sonha e cria, pode ser encontrado em Freud (1907-1908/1994, p. 127) em seu representativo texto "Escritores criativos e devaneios". Neste texto ele escreve:

todos, no íntimo, somos poetas... A ocupação favorita e mais intensa da criança é o brinquedo ou os jogos. Acaso não 
poderíamos dizer que ao brincar toda criança se comporta como um escritor criativo, pois cria um mundo próprio, ou melhor, reajusta os elementos de seu mundo de uma nova forma que lhe agrade?

Pensamos que, da mesma forma, no processo analítico é um "infantil" criativo que está em jogo. Assim, este processo pode ser comparado a um playground como Freud (1914/1994e, p. 156) mesmo sugeriu. Este termo foi por ele utilizado quando se referiu à transferência, estando no centro do trabalho de manejo do analista e da produção de novos sentidos do analisando. A transferência foi entendida também como sendo o espaço da brincadeira no qual o paciente pode atualizar e elaborar o que não recorda ou o que, compulsivamente, repete.

Em termos freudianos, no espaço da brincadeira encontramos um infantil que escapa à ordem temporal, cronológica. Da mesma maneira, este mesmo infantil não necessariamente nos possibilita sentirmo-nos "desamparados" ou tementes da perda do amor do semelhante (condições relacionadas à moralidade). Neste caso, ele não nos leva necessariamente a sermos moralmente autônomos, conforme o que se espera daqueles que adentraram o universo moral adulto.

\section{A título de conclusão}

A abordagem psicanalítica da infância nos sugere a constituição de modos de existência privilegiando o simbólico e o pulsional. Trata-se de processos de subjetivação que nos remetem à trama diferencial e ao âmbito da disseminação. Destaca-se, portanto, o jogo das forças disseminadas e das resistências produzidas em que os traços se inscrevem no psiquismo, podendo produzir novos sentidos.

Nessa perspectiva, o infantil diz respeito à condição de possibilidade de uma história, para além do jogo das identificações binárias e imaginárias, embora, numa perspectiva desenvolvimentista, ele seja um estágio necessário; mas numa perspectiva psicanalítica, ele permanece em nós, não se constituindo em estágio a ser ultrapassado. O paradoxo do infans participar da própria criação da subjetividade faz dessa concepção de infantil uma noção frutífera diante da sociedade atual. Afinal, nos possibilita vislumbrar que nossa história é também a história de nossa criação. E esse é um argumento importante diante de um contexto, como o nosso, de crise dos fundamentos que alicerçam a própria sociabilidade. Participamos de nossa própria constituição e construímos juntos. Não somos sujeitos autônomos, mas codependentes.

A partir dos textos freudianos, podemos afirmar que, se por um lado, as funções motoras, perceptivas, fonatórias etc. desenvolvem-se, por outro, elas também dependem do tipo de tratamento dado aos estímulos internos da criança. Podemos dizer, por exemplo, que a maturação harmônica do tônus muscular depende de uma espécie de diálogo tônico estabelecido pela mãe com sua criança (Jerusalinsky, 2004).
Esse diálogo pode capturar o corpo da criança. Nesse sentido, podemos dizer que o maturativo mantém-se como limite, mas não como causa do tônus apresentado, por exemplo, posto que este depende também de um interminável diálogo entre criança e outro.

Vimos que a trama epistemológica da obra piagetiana afirma que as estruturas cognitivas e afetivas da criança e as estruturas cognitivas e afetivas do adulto são qualitativamente diferentes. No entanto, o sujeito freudiano não permite o estabelecimento, tão facilmente, de diferenças entre crianças e adultos. Se, por um lado, a clínica psicanalítica depara-se com idades cronológicas diversas, por outro, o inconsciente nos remete a outros tempos que não o cronológico, fato que aproxima crianças e adultos.

Se nos textos piagetianos a dimensão cognitivo-racional norteia o julgamento de valores, nos de Freud os valores não obedecem apenas a juízos racionais. Nesse mesmo sentido, podemos dizer que se Piaget crê na possibilidade de o inconsciente tornar-se consciente, Freud nos lembra, com sua noção própria de inconsciente, que algo sempre escapa a essa pretensão. Da mesma maneira, se Piaget conclui que a afetividade pode provocar acelerações ou retrocessos no desenvolvimento das estruturas da inteligência, embora não possa produzir nem modificar essas mesmas estruturas, a afetividade em Freud ganha uma dimensão mais ampla. Ela, mais do que acelerar ou retroceder estruturas, pode produzir e modificar dimensões subjetivas muito amplas.

Outra diferença diz respeito ao fato de a epistemologia genética sustentar uma noção de desenvolvimento na qual a criança deva ser ultrapassada em nome de uma racionalidade formal. Já a psicanálise sustenta a existência permanente dessa criança (em qualquer sujeito, de qualquer idade), que é, inclusive, vista como fonte de experiências criativas e não como sintoma de infantilismo.

\section{Referências}

Birman, J. (2007). Escritura e psicanálise: Derrida leitor de Freud. Revista Natureza Humana, 9(2), 275-298.

Coriat, E. (1997). Psicanálise e clínica de bebês. Porto Alegre: Artes e Ofícios.

Costa, J. F. (2010). O ponto de vista do outro. Rio de Janeiro: Garamond.

Derrida, J. (2011). Freud e a cena da escritura. Em $A$ escritura e a diferença (pp. 289-338) (M. B. M. N. Silva, P. L. Lopes, \& P. Carvalho, Trads.). São Paulo: Perspectiva.

Dolle, J-M. (1979). De Freud a Piaget. Buenos Aires: Paidós.

Flusser, V. (2010). A escrita: há furos para a escrita? São Paulo: Annablume.

Freud, S. (1994a). Projecto de psicologia. Em Obras Completas 1 (pp. 
323-436). Buenos Aires: Amarrotu. (Trabalho original publicado em 1895).

Freud, S. (1994b). Carta 52. Em Obras Completas 1(pp. 274-280). Buenos Aires: Amarrotu. (Trabalho original publicado em 18921899).

Freud, S. (1994c). Tres ensayos de teoría sexual. Em Obras Completas 7 (pp. 123-224). Buenos Aires: Amarrotu. (Trabalho original publicado em 1905).

Freud, S. (1994d). El creador literário y El fantaseo. Em Obras Completas 9(pp. 127-136). Buenos Aires: Amarrotu. (Trabalho original publicado em 1907-1908).

Freud, S. (1994e). Recordar, repetir y reelaborar (Nuevas consejos sobre La técnica Del psicoanálisis, II). Em Obras Completas 12 (pp. 149-157). Buenos Aires: Amarrotu. (Trabalho original publicado em 1914).

Freud, S. (1994f). Introducción del narcisismo. Em Obras Completas 14 (pp. 71-98). Buenos Aires: Amarrotu. (Trabalho original publicado em 1914).

Freud, S. (1994g). Psicologia de las masas y análisis del yo. Em Obras Completas 18 (pp. 67-136). Buenos Aires: Amarrotu. (Trabalho original publicado em 1921).

Freud, S. (1994h). Nota sobre La "pizarra mágica". Em Obras completas 19 (pp. 243-248). Buenos. Aires: Amarrotu. (Trabalho original publicado em 1924-1925).

Freud, S. (1994i). La negacion. Em Obras Completas 19 (pp.253257). Buenos Aires: Amarrotu. (Trabalho original publicado em 1925).

Freud, S. (1994j). El malestar em La cultura. Em Obras Completas 21 (pp.65-140). Buenos Aires: Amarrotu. (Trabalho original publicado em 1929-1930).

Freud, S. (1994k). La descomposicion de la personalidad psíquica. Em Obras Completas 22 (pp.53-74). Buenos Aires: Amarrotu. (Trabalho original publicado em 1932-1933).

Jerusalinsky, A. N. (2004). Psicanálise e desenvolvimento infantil. Porto Alegre: Artes e Ofícios.

Kaufmann, P. (1996). Dicionário enciclopédico de psicanálise: o legado de Freud e Lacan (M. L. X. A. Borges, Trad.). Rio de Janeiro: Jorge Zahar Editor.

Lajonquière, L. (1992). De Piaget a Freud: para repensar aprendizagens. A (psico)pedagogia entre o conhecimento e o saber. Petrópolis, Rio de Janeiro: Vozes.

Maciel, M. R. (2011). O infantil ou o que não se desenvolve, mas cria. Childhood \& Philosophy, 7(14), 207-219.
Martins, K. P. H., Matos, T. G., \& Maciel, R. H. M. O. (2009). Formação em psicologia e as novas demandas sociais: relato dos egressos da Universidade de Fortaleza. Revista Mal-Estar e Subjetividades, 9(3),1023-1042.

Moscovici, S. (2003). Representações sociais: investigação em psicologia social. Petrópolis, Rio de Janeiro: Vozes.

Pascual, J. G., \& Dias, M. (2004). Fragmentos. Filosofia, Sociologia, Psicologia. O que isso interessa à Educação? Fortaleza: Editora Tropical.

Pascual, J. (1999). Autonomia intelectual e moral como finalidade da educação contemporânea. Psicologia: Ciência e Profissão, 19(3), 2-11.

Piaget, J. (1923). A linguagem e o pensamento na criança (M. Campos, Trad.). São Paulo: Martins Fontes.

Piaget, J. (1955). Inteligencia y afectividad. Buenos Aires: Aique Grupo Editor S. A.

Piaget, J. (1966). O nascimento da inteligência na criança (Á. Cabral, Trad.). Rio de Janeiro: Editora Guanabara. (Trabalho original publicado em 1936).

Piaget, J. (1970). A construção do real na criança (Á. Cabral, Trad.). Rio de Janeiro: Zahar Editores. (Trabalho original publicado em 1937).

Piaget, J. (1984). O juízo moral na criança (E. Lenardon, Trad.) São Paulo: Summus. (Trabalho original publicado em 1932).

Piaget, J. (1990a). A formação do símbolo na criança. (Á. Cabral, Trad). Rio de Janeiro: LTC. (Trabalho original publicado em 1945).

Piaget, J. (1990b). A formação do símbolo na criança. (Á. Cabral, Trad.) Rio de Janeiro: LTC. (Trabalho original publicado em 1946).

Piaget, J. (2001). Inteligencia y afectividad. Buenos Aires: Aique Grupo Editor. (Trabalho original publicado em 1954).

Piaget, J. (2005). A representação do mundo na criança (Á. Cabral, Trad.) São Paulo: Ideias e Letras. (Trabalho original publicado em 1926).

Piaget, J. \& Inhelder, B. (1994). A psicologia da criança (O. M. Cajado, Trad.). Rio de Janeiro: Bertrand Brasil. (Trabalho original publicado em 1966).

Tambiah, S. (2013). Múltiplos ordenamentos de realidade: o debate iniciado por Lévy-Bruhn. Cadernos de Campo, 22 (22), 193220. 


\section{Sobre os autores}

Maria Regina Maciel (mreginamaciel@terra.com.br)

Professora da Universidade do Estado do Rio de Janeiro (UERJ). Doutora em Saúde Coletiva.

Karla Patrícia Holanda Martins (kphm@uol.com.br)

Professora da Universidade Federal do Ceará (UFC). Doutora em Teoria Psicanalítica.

Jesus Garcia Pascual (professorpascual@gmail.com)

Professor da Universidade Federal do Ceará (UFC). Doutor em Educação.

Osterne Nonato Maia Filho (osterne_filho@uol.com.br)

Professor da Universidade Estadual do Ceará (UECE) e da Universidade de Fortaleza (UNIFOR). Doutor em Educação.

Infância e infantil: Piaget e Freud * Maria Regina Maciel, Karla Patrícia Holanda Martins, Jesus Garcia Pascual \& Osterne Nonato Maia Filho 
